

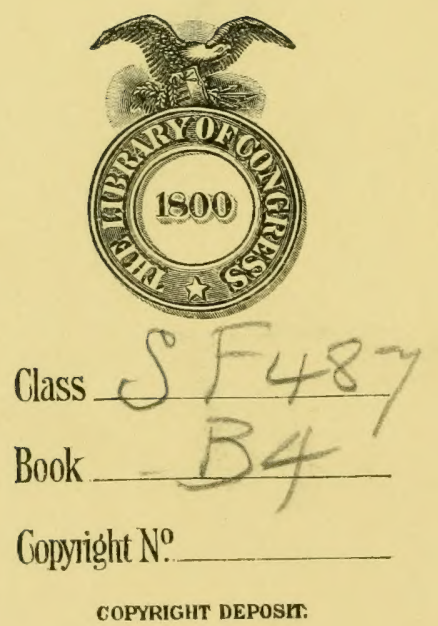




A Living from

Poultry....

$$
* t \text { OR } * x
$$

The Friendship Sustem of Poultry Keeping

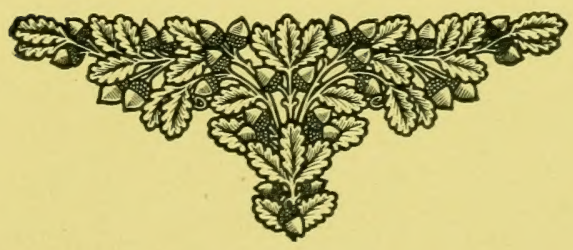

Price \$1.00 Por Copy.

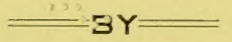

W. A. BELL

ANACOSTIA, D. C. 


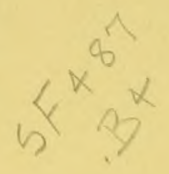

\title{
COPYRIGHT APPLIED FOR
}

$\mathrm{BY}$

\author{
W. A. BELL \\ Anacostia, D. C. \\ MARCH, 1911
}

$\because \vdots \vdots$

2

(C) Cl.A284190 


\section{INTRODUCTION.}

A few years ago I started in the chicken business in a small way, the people had never seen chickens raised as I was raising them at this time. There was so many requests for information, that I begun to wonder what I could do to help the people who were seeking this information. Last August I was invited to read a paper before the Business League in New York, after reading the paper I was flooded with letters from all over the country for information, so I decided to publish this book, hoping that it will benefit thousands of my fellow beings who are struggling to better their conditions.

I have tried to make everything as plain as I possibly could. I expect to follow the chicken business for many years to come and expect to experiment and find out everything that is a benefit to the business and a help to the people who are in the business. My findings will be published in Bulletin or Book form, of which the public will be notified.

There is much to learn about the chicken business, and I hope that every purchaser of this book will join me in studying how to improve the business, which will most certainly increase our poultry profits.

YOURS FOR SUCCESS.

W. A. BELL,

Anacostia, D. C. 


\section{LIST OF ILLUSTRATIONS}

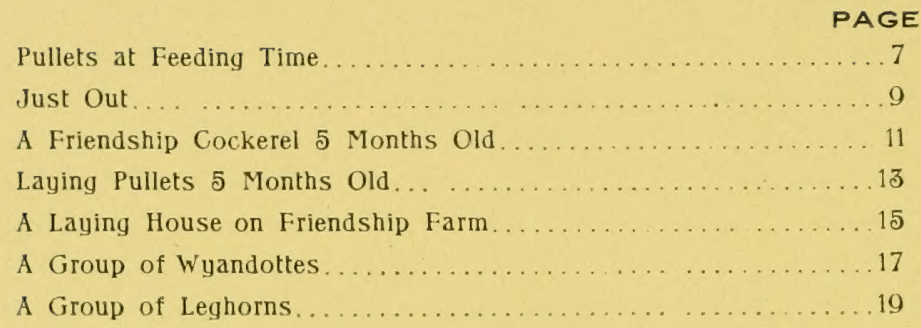

\section{CONTENTS}

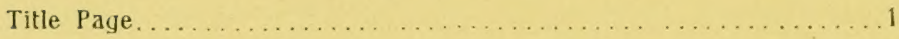

Copyright . . . . . . . . . . . . . . . . . . . . 2

Introduction $\ldots \ldots \ldots \ldots \ldots \ldots \ldots \ldots \ldots \ldots \ldots \ldots \ldots \ldots \ldots \ldots$

Location. . . . . . . . . . . . . . . . . . .

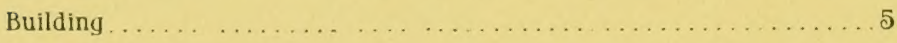

Incubating . . . . . . . . . . . .

Turning and Cooling The Eggs ................. $\delta$

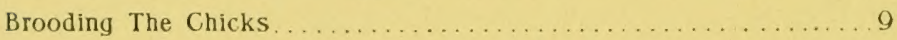

Feeding The Chickens .... . . . . . . . . . . . . . . . . 11

Selection of Breeders . . . . . . . . 13

Pullets or Yearling Hens ..................... 14

How To Select Laying Hens . . . . . . . . . . . . . . . . 14

Lice and Mites ........................... 14

Drinking water................................ 15

Green Bone............................... 15

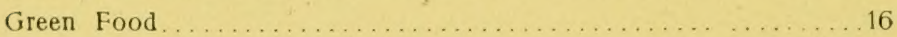

How To Keep Fresh Eggs. . . . . . . . . . . . . . . 16

Fattening The Cockerel. ....................... 17

Cleanliness ................................ 18

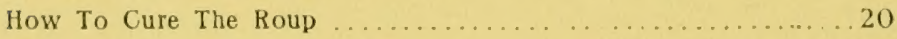

How To Make A Food Hopper....................... 20

New Feed Experiments............................ 21

A Day With The Chickens on Friendship Farm ........... 22

The Publisher's "Ad." .......................... 23

The Printer's "Ad." ........................... 24 


\section{LOCATION}

T 7 S SELECTING A SITE for your poultry plant, you must see that it is located on a well drain-

ed plot of ground. The house should point a little east of the direct south. The direct south would be alright were it to be continual summer, but when winter comes you will need all the sun radiation that you can find and the slight turn to the east will provide it when it will do the most good. This position will shelter the building from the west and the northwest winds.

Before you start to build, consider well the question of drainage. The surface water should run from the house and not toward it, and you must be careful that moisture cannot collect under or around the house, for in that way you endanger the health of the birds.

\section{BUILDING}

In building the house you can have one pen or you can have five, I would advise that you only have five, or not over five if you care to have that many in one house. If you have over five they will not be so easy to attend to.

I will now tell you how to build the house. After having the location and the direction in which you want your house, stake off the ground allowing the pens to be 10 feet wide and 16 feet deep. A house 50 feet long will give you five pens.

After laying off the lines for the building, you make a foundation wall of cement, the wall to be 4 inches thick so as to earry a 4 inch sill, this wall is to be 6 inches in the ground and 6 inches above the ground. After the wall is complete, fill in the entire inclosure with stones, gravel or ashes, until it is about 2 inches from the top of the wall, fill the remaining 2 inches with cement, you will then have a floor that will be rat proof and damp proof and one that will last you a life time.

Your sills are to be $4 \mathrm{x} 4$ inch lumber. The house is to 
be 7 feet high in the front and 5 feet high in the back. The uprights are to be of $2 \times 4$ inch studs, placed 3 feet apart. At the corners I use $4 \times 4$ inch studs. The plates are made of $2 \times 4$ inch studs, the rafters are of $2 \times 6$ and have no projections beyond the plate. This makes it easier to make the back wall air-tight. For the back and sides I use a good Russet siding or 6 inch tongue and grooved flooring and fit the joints as tight as I can possibly get them.

The front must be boarded up 2 feet from the bottom of the sill and 2 feet on each side of the pens, leaving an opening $6 \times 5$ feet to be covered with a 1 inch wire mesh. The door is to be in the east side of the house and near the front. Between each pen you must have a tight partition of tongue and grooved boards, running from the floor to the roof, you must allow 3 feet at the extream front of the partition for the door. The door should be $5 \frac{1}{2}$ feet high and swing 1 foot clear of the floor, so that it will not interfere with the litter that is to be put on the floor. The other foot at the bottom of the door is to be boarded up.

The drooping boards are placed 3 feet from the floor against the back wall, this leaves a plenty of room for the hens to work in the litter under them. This height also leaves sufficient room for the attendant to easily gather any eggs that might be laid under them. The roost is made of $2 \times 3$ inch studs with the edge plained off and placed 1 foot above the drooping boards, the ends resting on pieces nailed to each wall 1 foot above the drooping boards and are notched so that the roost will fit into them. The first perch is placed 12 inches from the back wall and the succeeding ones are placed 15 inches apart, allowing 3 perches to a pen. The front of the drooping boards are 15 inches in front of the first roost.

Beginning at a point level with the drooping boards, we board up the back walls with tongue and grooved boards, clear to the cealing, this makes a double wall for the back or north side of the house.

The roof is made of $\frac{7}{8}$ sheathing, on top of which is laid a 2 ply roofing paper. Being very careful to cement the 
joints and nail it down well. Care should be taken so as to have the paper lap at all corners and joints, and around the ridges, so as to prevent any draughts from getting in at these points.

You must make a curtain of muslin to cover the entire wire front of the house, this curtain is to be let down on cool nights and raised in the day after the sun is up. You must also have another curtain directly in front of the roost, to be let down on real cold nights to protect your birds and keep them comfortable. This curtain is raised in the morning after the chickens are off the roost.

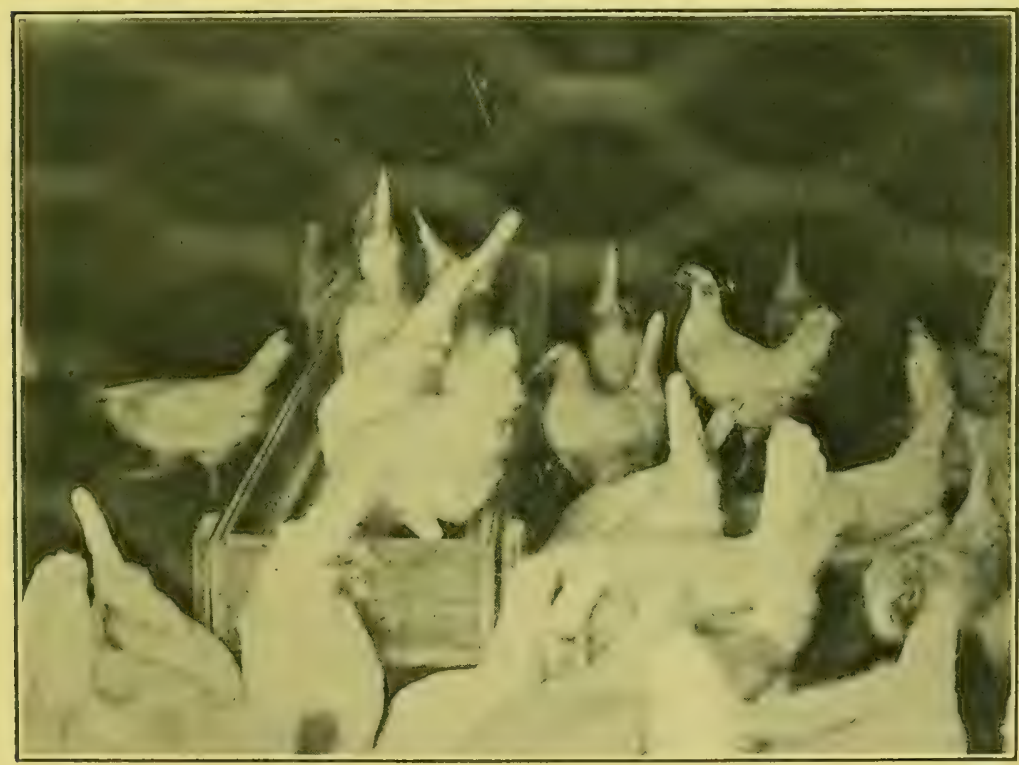

\section{Pullets at Feeding Time.}

When the house is complete I cover the floor with sifted garden soil to the depth of about 3 inches. Get it good and dry and it will last you a year I renew it every fall. The way that $I$ do is, every wheel-barrow of earth that $I$ take out I put another fresh one in the place of the one carried out, as soon as I get the earth out of the house and on the ground, 
I sow it in kale or crimson clover, if kale, I have it to cut all the, winter as green food, if clover I have it to feed in the spring:

\section{INCUBATING}

When I first start my incubators I usually run them two or three days so as to make absolutely sure that the thermometer is correct and that the temperature is the same in all parts of the machine.

The correct temperature should be 102 the first week, 10:; the second week 10:3 to 10 t the third week. after seeing that the temperature is alright. I fill the machine with well selected medium size clean eggs free from any flaws in the shell. The first day I do not touch them. The second day I just simply pull the tray out and turn it end for end, on the morning of the third day I start to turn my eggs. I turn them twice arch day until the night of the eighteenth day, I test my eggs on the ninth and eighteenth days. On the night of the eighteenth day I take a cloth and soak it in warm water, then I wring it almost dry, spread it over the eggs and leave it until the morning of the nineteenth day, this softens the shell and makes it easier for the chicks to get out. Even then I find that there are some chicks that cannot pick their way out. I take my pocket knife and pick a hole in the large end of the egg being very careful not to breals the inner shell or skin, put the egre back in the macine under a moist cloth and in that way save many chicks that would otherwise be lost.

\section{TLRNING ANI) COOLING TILE LGGS}

In turning the egres I place a block or book under one end of the tray, remove an egg from a row and let all the rest down gently, this does not jar the egg's and is a safe method. It is best to turn all egors by hand in all blank 
trays I cool the eggs to a temperature equal to luke warm water, then replace them in the machine again. Never cool eggs in a temperature below 60 as it is a positive injury to do so.

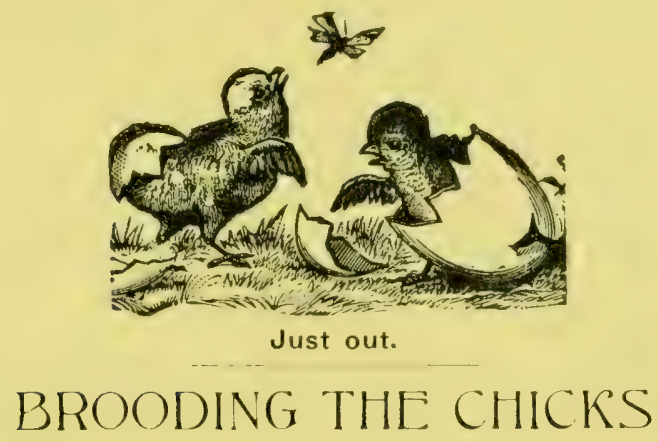

Be sure and get the very best brooder that you can buy, get an indoor brooder. Then divide one of your pens into three small pens and put a brooder into each pen. This will give you three brooders in one of your large pens $10 \mathrm{x}$ 16. Do not put over 50 chickens in each brooder.

These small pens do not come all the way to the front of the house, I leave a 2 foot space for a passage way, the brooders are put in the front end 2 feet from the front of the house, facing the back of the house. I use a 2 foot 1 inch mesh wire, so that you can step from pen to pen without any trouble, this wire runs back to the back wall under the drooping boards, as I do not move the dropping boards because the chickens will use them when they are old enough. I also run a 2 foot wire along the back of the brooders to keep the chickens from getting in the passage way.

Your brooder should be heated according to the directions of the maker, your chicks should be put into the brooder as soon as they are dry in the incubator, you should not feed them for 48 hours after they are taken from the machine. (see feeding) 
The chickens should not be allowed to get more than a foot away from the heat the first day, two feet the second day and three feet the third day. After that they can have the use of the whole run. You must watch them very carefully and see that they all get back safely without (dhilling. After the third day they will run in and out of the brooder without any trouble.

After the chicks are four weeks old they should not have any more heat. In fact, after that heat is very injurious to them, they will grow faster and be more healthy, if not given any heat, but handled as I tell you.

Build a box $2 t$ inches square, 8 inches deep, with a removeable top, $\frac{1}{2}$ inch lumber is best, have a tight board bottom. Across the sides nail 2 slats about 5 inches from the floor, make a frame of laths just to fit inside of the box resting on top of the slats. Cover the frame with burlap or muslin, allow the burlap) or muslin to bag down about ¿ inches below the center of the frame or 3 inches from the floor in the center of the box. Have an opening in the center of the box $3 \frac{1}{2}$ inches square, at the top of the box on 2 sides at the center make an opening 1-5 inch, this serves as a handle as well as for ventilation.

Line the bottom part of the box with felt on the sides, and cover the Hoor with cut clover, cut hay, or dried leaves. I like the leaves the best, as they do not pack and are not heavy for the little chicks to scratch in.

Now make a cushion of cotton batten and cover it with burlap or muslin and make it to tit the inside of the box on the frame, this cushion is to be made about 2 inches thich.

After having your cold brooder ready, drive all the chickens out of the heated to the far end of the pen, then place the brooder box in the pens, in front of the heated brooder. Closing off any chance that they may have in getting back to the heated brooder. When this is done late in the afternoon, I find that they will nearly all go in the box, without any trouble. 5o chicks in a pen will make enough heat to keep them comfortable. We keep the chickens in this box until they are 6 or $T$ weeks old. 
When the chicks are 6 or 7 weeks old, I make another box 2 feet wide, 3 feet long and 12 inches high in front and 1) inches in the back, with a removeable tol) and a tight board bottom. I use $\frac{1}{2}$ or $\frac{7}{8}$ inch lumber for this box, the opening in front for the door is one inch, and at the top on each side $\frac{1}{3}$ inch for handle and ventilation. Drive the chicks out as you did before and place the box in the place of the smaller one. As soon as the chickens get so that you cannot keep them in the small runs, remove the wire and let them all run together in the one large pen, but they must all be of one age. They will divide up and go in their own box at night.

Always start your chickens in the last pen if you have mole than one, and the next in the next pen and so on, al ways keeping the youngest chicks near you.

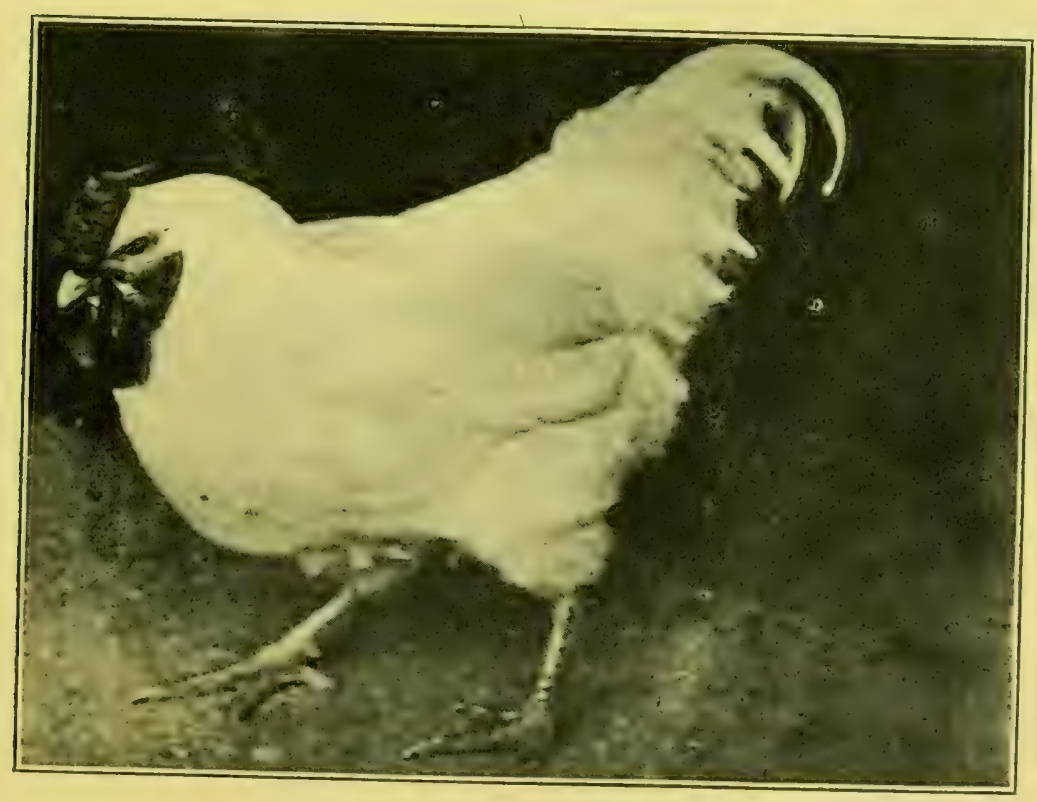

A Friendship Cockerel 5 Months Old.

\section{FEEDING THE CHICKENS}

Remove the chicks from the Incubator as soon as they 
are dry and put them into the brooder under the hoover, do not try and feed them until they come from under the hoover and cry for something to eat.

The first food should be rolled oats ground to meal in a food grinder, mixed with equal parts of toasted bread (stale bread) ground in the same manner. This bread should be toasted as hard as possible. Do not give them anything else but clear clean water with the chill off.

We make a small shallow box of packing box lumber, six inches wide and two feet long, sides two inches high.

Two one-inch strips nailed long-ways across the top. This is kept full of the oat and bread mixture; after three days we add 10 per cent of good beef scrap to the mixture.

All chickens that do not come from under the hoover but act sluggrish or droopy, should be taken away from the others and put to themselves. These chickens should be sold as soon as they are large enough, they should never be kept, as they will never produce satisfactory results.

We keep our brooder floors covered with about three inches of dry leaves and find it better than any other lind of litter that we have ever used, as it does not pack. In these leaves we satter some good commercial chick feed, four times a day; this induces exercise and prevents lear weakness. After the chickens are a week old, we keep before them oyster shells, grit, charcoal and beef-scrap at all times.

When the chickens are a week old, we change the oat and bread mixture and feed two parts wheat brand, two parts corn meal and two parts beef-scrap. We keep this before them all the time; once a week, we add a spoonful of (ayenne pepper, sulphur, sulphate of soda, flaxseed meal, salt. and ringer to stimilate and keep their systems in wood order.

After the third day, the chickens must be fed some green food, we usually feed it at noon; lettice, kale, cabbage or sprouted oats, this must be supplied every day. When the chickens are six weeks old, we feed two parts middlings, two parts brand, four parts corn meal, one part linseed meal, and two parts beef-scrap), also mix a spoxnful of (alyenne pep)- 
per, sulphur, etc. once a week. We now feed in the litter equal parts of wheat, cracked corn, kaffir corn, and hulled oats. we feed this night and morning. (see hopper)

At $4 \frac{1}{2}$ or 5 months of age, your pullets should be laying or about to begin laying. At this age, we feed one part of grounded oats, two parts of corn meal, two parts of wheat brand, one part of beef-meal, and one part of linseed meal, add once a week a handful of cayenne peper, sulphur, etc. In the morning we feed equal parts of cracked corn, wheat and oats; at night we feed, one-half part of wheat and oats and two parts of cracked corn. All the grain is fed in the -litter, all the mash is fed dry in hoppers. (see hopper)

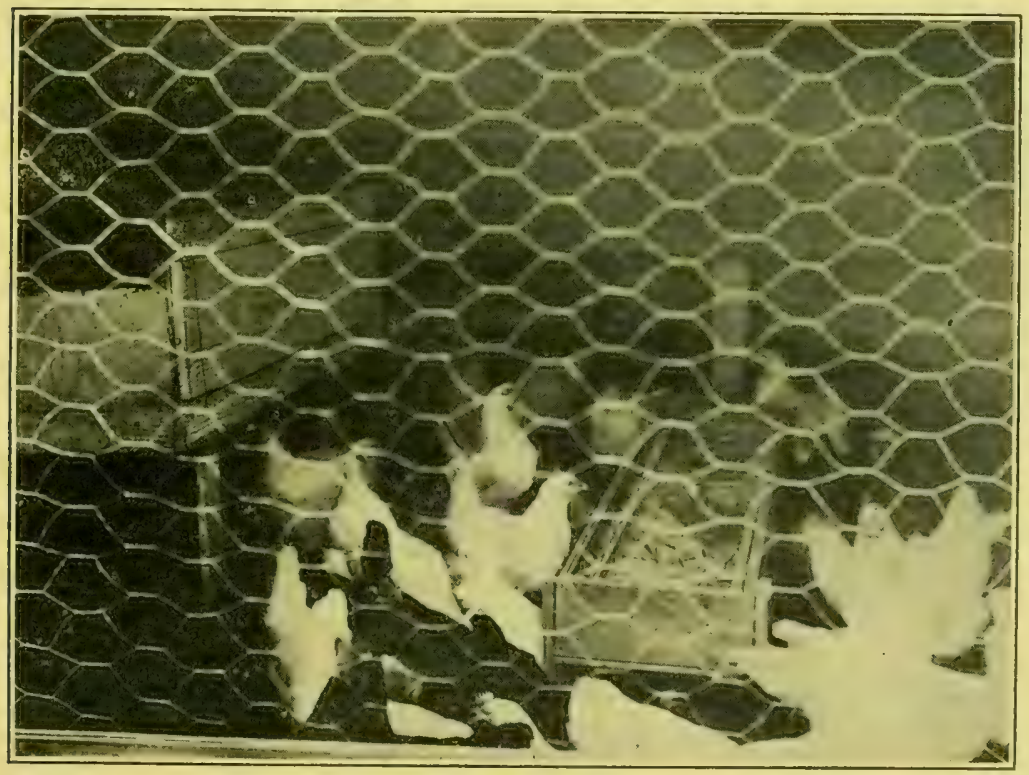

Laying Pullets 5 Months Old.

\section{SELECTION OF BREEDERS}

Selecting the breeders, may well be considered the success or failure in the poultry business, and it should receive your careful thought. You are going in the business 
to make money, so do not be contented with scrub stock for it makes a poor investment. You must get the very best birds that you are able to buy. This is the rock on which many poultrymen fail, so be sure and start right. You must breed from only the strongest and most vigerous birds that can be found.

\section{PULLETS OR YEARLING HENS}

The best beginning is made with healthy, thrifty yearling hens. They will not only give you a satisfactory winter egg yield, but will produce stronger and better chicks in the spring. Fifty hens should lay you twenty-five hundred eggs between October the first and June the first. If five hundred of these eggs are incubated, there should be from three to four hundred chickens hatched and the remaining two thousand eggs should bring you about $\$ 40.00$. The value of the chickens the first year should not only pay for the cost of the stock and feed but should also pay part of the cost of the buildings and fixtures. Pullets hatched during March, April and May and cared for the Friendship way should begin laying in the fall, and continue laying right through the winter.

\section{HOW' TO SELECT LAYING HENS}

A grood and absolutely sure test is after the hens have gone to roost, take a lantern and go in the hen house and feel the hens' ('aws. The ones that have good, big, full craws you can brand as good egg producers and are valuable hens, the ones that you want to breed from. Those that have craws about the size of a marble should be discarded as they will never make good layers.

\section{LICE AND MITES}

A lousy hen will never lay eggs enough to pay for her 
feed. I take five pounds of sulphur and five pounds of naphthaline and mix it with a wheel-balrow of hald coal ashes and put it in boxes for them to dust in. I put lime in the bottom of the nest and hay on top of it and in that way I am never troubled with lice or mites.

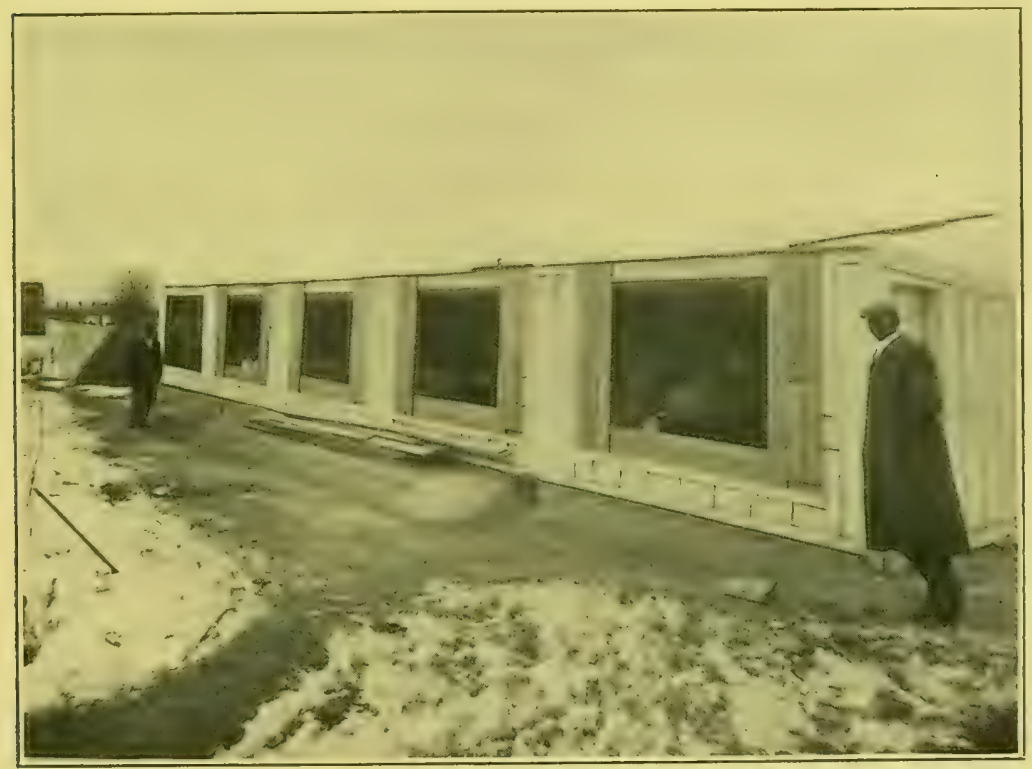

A Laying House on Friendship Farm.

\section{DRINKING WATER}

The hens and chickens should be given nothing but fresh, clean, clear, pure water to drink. The drinking vessels should be washed and cleaned every day, you cannot be too careful about the water that you give them to drink as the greater part of the egg is made of water.

\section{GREEN BONE}

Mother nature probably knew what she was about when 
she gave the hen such an appetite for worms, bug and grubs. When these can not be found, we must find a substitute for them, and the greatest substitute known to the poultry world is ground green bone.

Ground green bone is cheap in price and very nutritious, easily digested and greatly relished by the fowls, it is similating and strengthing to the egg organs. Very great care should be used so as not to feed any spoiled bone or meat as it might cause an aggravated case of diarhea, which is practically incurable. I feed an average of about an once of bone a day to each hen.

\section{GREEN FOOD}

Take a good quality of white clipped oats, one bushel will make four when sprouted. The oats are placed in a water tight vessel and covered with warm water and allowed to stand for twenty-four hours, then they are emptied into a box that will allow the water to drain off freely. Oats are left in this box and wetted twice a day with warm water until the oats have sprouted, then they are spread in boxes about an inch deep. You continue to sprinkle until the oats are as large as desired, which is about four or five inches in length. The hens will eat roots and all.

With a temperature of about 60 , it will take about ten days to sprout them, after the first day you can provide for each days green food. Chickens a week old will eat them, in fact, will leave everything else for them.

\section{H() MO TO KEEP FRESH EGGS}

After the breeding season is over and the demand for roges for hatrhing and market purposes are not so great, and prices are low, I pack my eggs and keep them for better prices.

First, I separate my male and females. The eggs then are infertil and will dry up before they will spoil. I get a 
whiskey barrel and put bran in it and set the eggs on the sharp end, the big end up. I put in a layer of bran and a layer of eggs, until the barrel is filled. I then get some heavy wrapping paper and seal the barrel, I put the paper over the barrel as tight as I can get it, then glue or paste it all around, then I put on two or three more layers, one at a time and paste them down tight, then I tie a string around it to make sure that it is tight and no air can get in it. I then put the barrel in a cool dry place.

Along about the first of December when the price of eggs are high and the demand is the greatest, I put these

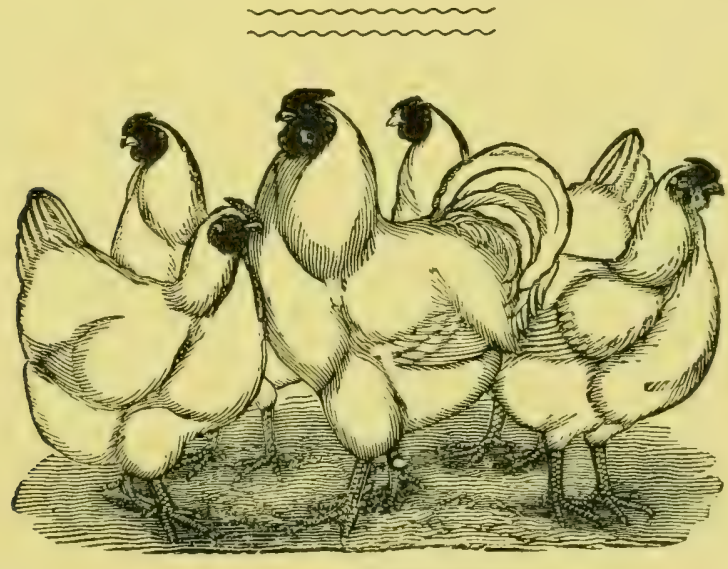

A Group of Wyandottes.

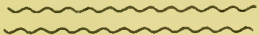

eggs in a crate and send them to town, and they bring from 30 to 50 cents a dozen. And are far superior to any cold storage eggs that can be found.

\section{FATTENING THE COCKEREL}

The cockerels are separated from the pullets as soon as I am able to distinguish the sexes, and all that $I$ do not in- 
tend keeping for breeders are fed for market. I place 100 cockerels in one of my pens $10 \times 16$ feet, in this way I find that they make a more rapid growth than when crate fattened and bring a higher price than they would other-wise. I place two $\mathrm{V}$ shape troughs in the pen, they are about 8 feet long, in them I feed two parts ground oats, two parts buckwheat meal, two parts corn meal, mixed with skim milk to the consistency of a thin porridge. This mash should be prepared about 12 hours before it is fed so that it will have time to ferment a little, thus rendering it more fat producing. The mash is fed twice a day, and every other day I add a handful of salt and pepper to keep up their appetites. Ocasionally I use molasses instead of the sour milk, this makes a very rich and nutritious feed.

I plan to feed this mash about three weeks, and in the last ten days I mix in $\frac{1}{2}$ ounce of tallow per bird per day, keeping water before them all the time. Do not feed anything for ent hours before killing, you will be surprised at the fine quality of bird that you will have to sell.

\section{CLEANLINESS}

The (looping boards should be kept sprinkled with ashes, and cleaned at least three times a week. The litter should be removed whenever it becomes heavy and packed, and new litter put in its place. The dust baths should be kept filled with dusting material. Spray the houses with a solution of one half pint of crude Carbolic Acid, to fifteen pints of kerosene or coal oil. Do this at least once a week, but it is better to do it twice instead of once, the nest should be treated the same as the rest of the house, all the fixtures should be treated the same way.

After all has been said in regald to a proper system of feeding your poultry, profits will be nothing unless every other point in the care of your fowls is carefully looked after. Fowls have a delicate nature, the same as any living creature and they must have good care if they are to be 
kept in good health. Sickness and death among your fowls might come from any of the following reasons:

Damp, unclean and unsanitary quarters. Too much wet or cooked food. Lice and mites. Unsanitary roost and nest boxes. Drafts in roosting room. Moldy and dirty straw for scratching litter. Lack of a good dusting bath. Neglect of caring for sick birds. Too many fowls in one room. Stale and filthy drinking water.

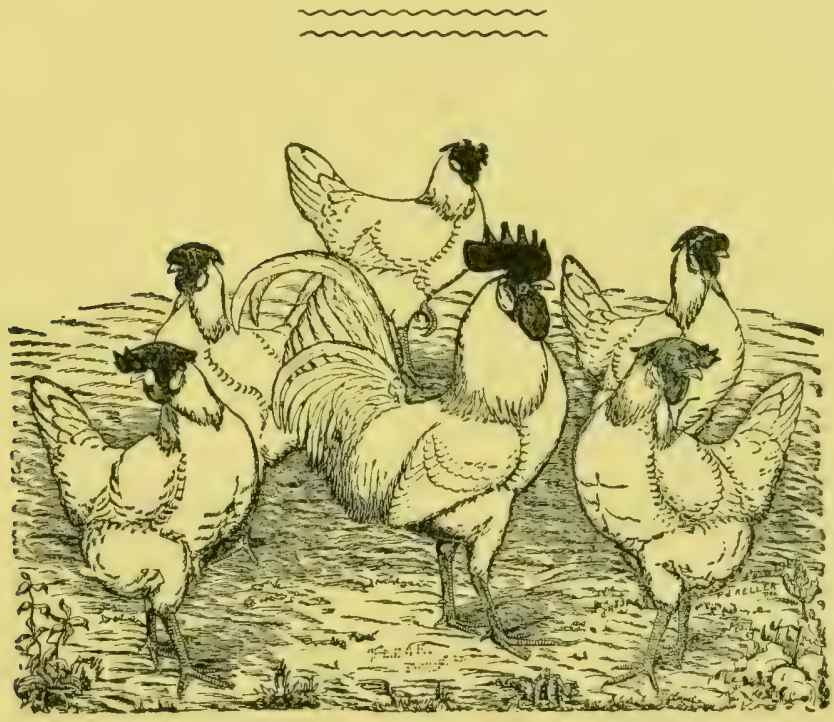

A Group of Leghorns.

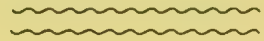

Hens cannot and will not lay if they are not in good health and properly fed, therefore, to get paying results any poultryman must be constantly on the alert to keep his fowls in the best condition. Keep in mind the points just mentioned and I dare say that you will have little occasion to talk about sickness among your fowls. 


\section{HOW TO CURE THE ROUP}

The first symptoms of roup appearing in your flock will be the wheezy and apparent stopped up condition of the throat and nose and a watery discharge from the nose. The fowls have spells of sneezing and will set around and act very dumpish and will not eat any food. Those showing these signs apparently have only a slight cold, but you must be on your guard and be prepared to fight the disease in its first stage.

First I give a spoonful of castor oil, then I give a two crain quinine pill three times a day. You must have an oil (an, one like those used to oil machinery, only smaller, then remove the top and replace with a cork which fits tight, make a hole in the cork and insert a quill from a good size feather, cutting the top off so that a good size stream of oil (an How through. Now take your can and force some oil up each nostril and then into the roof of the mouth, in the slot that you see there, be sure and get it in there by all means, if you do not an abscess will form and if it does, you had better kill the bird. If you follow this treatment it is a sure cure.

\section{HON TO YAKE A FOOD HOPPER}

I take two pieces of six inch flooring, five feet long, nail them together, this forms the bottom. Two more pieces the same length form the sides, and two short pieces one foot long form the ends, you then have a box 5 feet long, 1 foot wide and 6 inches high. Now make a frame of 1 inch material that will just fit nicely in the box. or about $\frac{1}{2}$ of an inch smaller than the box on all sides. Cover this frame with one inch wire mesh, fill the box and lay this follower inside of the box on the feed with the wire side down so that the ends cannot cut the chickens, for young chicks I set the box flat on the ground and feed in this hopper as soon as the chicks are too large to eat from the small 
hoppers. For large or grown birds I add legs and raise it one foot from the ground. This makes one of the best hoppers that you can use as there is absolutely no waste and the chicks have to eat every bit of the food that is placed in it,

\section{NEI FEED EXPERI.'LNTS}

In the last few months I have been experimenting with a new bone that has not long been on the market, and I find that it gives grand results. I mix a mash as follows: 200 pounds corn-meal, $10(0)$ pounds gluten-meal, $10(0)$ pounds wheatmiddlings, 100 pounds wheat-brand, 50 pounds superfine hen-e-ta bone, 100 pounds number 1 hen-e-ta bone. This is put in a hopper and fed to the chicks from the time they are two days old, until you are through with them, never letting them be without it. I feed sprouted oats twice a day, and grain only once a day and that is for the evening meal, I feed enough so that some will be left over for morning.

I feed the following mixture: 200 pounds cracked-corn, 50 pounds kaffir-corn 250 pounds cracked-wheat; this is fed to the small or growing chicks. To the laying hens, I feed the following: 100 pounds cracked-corn, 100 pounds wheat, 100 pounds barley, 100 pounds oats. The grain is fed in the litter and the mash in the hoppers as same as formerly.

Under this new experiment I am getting more eggs than I ever did before and with almost half the trouble.

NOTICE. If you cannot get this bone in your section, I will ship it to you f. o. b. Washington; or Anacostia, D. C. at $\$ 2.50$ per 100 pound sack.

In useing this bone you do not use any other bone, grit, oyster-shells, meat-scraps, charcoal or anything of that kind. 


\section{A Day with the Chickens on Friendship Farm.}

\section{GOOD MORNING.}

6:30 a. $m$. Turn and cool eggs in the incubator.

8:00 a. m. Water the chickens, giving warm water in the winter and cool water in the summer. The curtains are raised at this time.

9:00 a. m. Feed sprouted oats.

10:00 a. m. Glean droopings.

11:00 a. m. Gather eggs, mark and date all breeding eggs.

12:00 m. Feed turnips, kale or cabbage.

1:00 p. m. Water the chickens.

3:00 p. m. Feed sprouted oats.

3:30 p. m. Gather the eggs, etc.

4:30 p. m. Feed the evening grain, 1 pint to every twelve hens.

5:00 p. m. Put down the curtains, rake up all straw into a pile in each pen in the center of the floor, throw your morning grain into this pile.

5:30 p. m. Empty the water in the pens, gather the eggs if any; lock up for the night.

6:30 p. m. Turn and cool the eggs in the incubators, trim and fill the incubator lamps. 


\section{Friendship Poultry Farm}

-Breeders of The-

FRIENDSHIP STRAIN

$=\mathrm{OF}=$

...Great Winter Layers...

White Wyandottes, Leghorns
White and Bround LeghOrns

BRED AND REARED UNDER THE

FRIENDSHIP SYSTEM OF POULTRY KEEPING

STOCK FOR SALE

Friendship Poultry Farm

ALABAMA AND STANTON ROADS,

Anacostia, D. C. 
If You Want To Advertise,

Get My Style of Printing.

\title{
Joseph H. Carioll ARTISTIC
}

\section{Book, Job and Catalogue

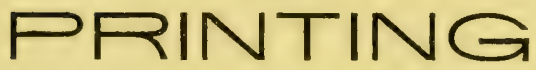

(¿ET YOUR PRINTED MATTER ILLUSTRATED WITH MY CUTS AND HALF=TONES. THEY HELP TO SELL, YOUR GOODS.

Estimates Mailed to any Address.

\author{
70 G Street, Southwest, \\ WASHINGTON, D. C.
}





LIBRARY OF CONGRESS 